
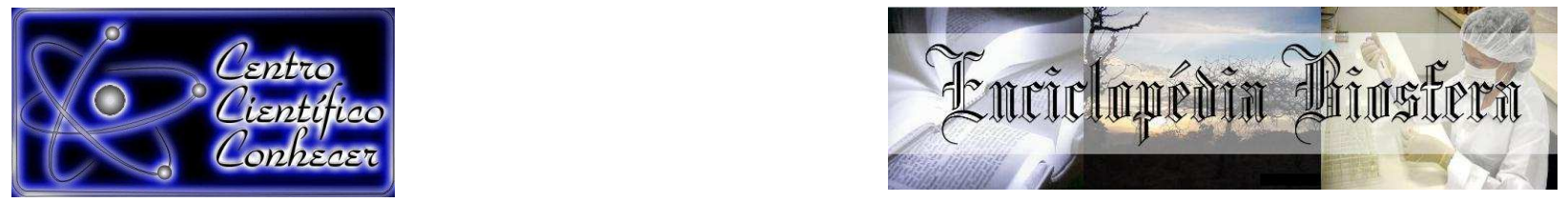

\title{
BIOPRECIPITACCÃO DE CARBONATO DE CÁLCIO POR BACTÉRIAS UREOLÍTICAS E SUAS APLICAÇÕES
}

\author{
Luann Guilherme Vieira dos Reis ${ }^{1}$, Ariana Alves Rodrigues², Renan de Sousa \\ Soares ${ }^{1}$, Renato Costa Araújo ${ }^{3}$, José Daniel Gonçalves Vieira ${ }^{4}$ \\ 1 Mestre em Ciências Ambientais, Universidade Federal de Goiás \\ 2 Mestre em Medicina Tropical, Universidade Federal de Goiás \\ 3 Professor Mestre do Núcleo de Pesquisa em Construção Civil (NUPECOCI), \\ Instituto Federal de Goiás \\ 4 Professor Doutor do Instituto de Patologia Tropical e Saúde Pública, Universidade \\ Federal de Goiás (jdgvieira62@gmail.com, Goiânia, Goiás, Brasil, 74605-050.
}

Recebido em: 02/10/2017 - Aprovado em: 21/11/2017 - Publicado em: 05/12/2017 DOI: 10.18677/EnciBio 2017B74

\begin{abstract}
RESUMO
A biomineralização é uma alteração química em um ambiente através de atividade microbiana que resulta na precipitação de minerais, sendo um fenômeno amplamente distribuído na natureza. Na precipitação de carbonato de cálcio induzida microbiologicamente (MICP, do inglês microbially induced calcium carbonate precipitation), a urease apresenta papel importante ao hidrolisar a ureia, por uma grande variedade de micro-organismos capazes de produzir elevados níveis desta enzima. Existem diferentes polimorfos do cristal de carbonato de cálcio e a estrutura que é formada depende do tipo da fonte de cálcio utilizada, período de incubação e atividades metabólicas referentes à espécie microbiana avaliada. A MICP é uma alternativa promissora e ambientalmente amigável para as tecnologias de remediação atuais e convencionais capazes de resolverem problemas ambientais em campos multidisciplinares. Várias aplicações como aumento da qualidade e da melhoria das propriedades de materiais de construção, remoção de metais potencialmente tóxicos e radionucleotídeos e sequestro de dióxido de carbono atmosférico têm sido discutidas.
\end{abstract}

PALAVRAS-CHAVE: Biomoneralização, carbonato de cálcio, construção civil, MICP, urease.

\section{CALCIUM CARBONATE BIOPRECIPITATION BY UREOLYTIC BACTERIA AND ITS APPLICATIONS}

\begin{abstract}
Biomineralization is a chemical change in environment through the microbial activity that results in the precipitation of minerals, being a phenomenon widely spread in nature. In microbially induced carbonate precipitation (MICP), ureases plays an important role in hydrolyzing urea by a large variety of microorganisms capable of producing high levels of this enzyme. There are different polymorphs of calcium carbonate crystal and the structure that is formed depends on the type of calcium used, the incubation time and metabolic activities of the evaluated microbrial species.
\end{abstract}


MICP is a promising and environmentally friendly alternative to current and conventional remediation technologies capable of solving environmental problems in multidisciplinary fields. Several applications such as increased quality and improved properties of building materials, removal of potentially toxic metals and radionucleotides and sequestration of atmospheric carbon dioxide have been discussed.

KEYWORDS: Biomineralization, calcium carbonate, construction, MICP, urease

\section{INTRODUÇÃO}

A biomineralização é o processo perante o qual organismos vivos sintetizam minerais inorgânicos. A precipitação de carbonato de cálcio $\left(\mathrm{CaCO}_{3}\right)$ é um exemplo conhecido de biomineralização promovida por células bacterianas e suas respectivas atividades metabólicas. Na precipitação de carbonato de cálcio induzida microbiologicamente os micro-organismos são capazes de secretar um ou mais produtos metabólicos que reagem com íons cálcio no ambiente resultando na precipitação de minerais (DHAMl et al., 2013a).

A biomineralização pode produzir diferentes fases de polimorfos anidros de carbonato de cálcio tais como calcita, aragonita e vaterita, bem como fases cristalinas hidratadas tais como monohidrocalcilta, ikeita, e carbonato de cálcio amorfo (ACC) (DHAMI et al., 2013b; ANBU et al., 2016). O processo de MICP é uma técnica efetiva e ambientalmente "amigável" que pode ser aplicada em diversas formas, incluindo a remediação de íons cálcio, radionucleotídeos e metais potencialmente tóxicos, sequestro de $\mathrm{CO}_{2}$, restauração de calcário em prédios históricos, bio-estabilização de solos e taludes, biocimentação, proteção da superfície de argamassas e concreto, remediação de fissuras dentre outras aplicações (ABO-EL-ENIEN et al., 2013; CUNNINGHAM et al., 2013; PHILLIPS et al. 2013; MANI : KUMAR, 2014; RODRIGUEZ-NAVARRO et al., 2015).

A MICP foi proposta como resultado de diferentes mecanismos como a redução de sulfatos (BONTOGNALI et al., 2014), fotossíntese (DE NOOIJER et al., 2014), hidrólise de ureia (JIANG et al., 2016), oxidação anaeróbica de sulfureto (WARTHMANN et al., 2000), formação de biofilme e substância polimérica extracelular (BHADURI et al., 2014). Contudo, a precipitação de carbonato de cálcio por bactérias via hidrólise da ureia é o método mais amplamente utilizado (DE MUYNCK et al., 2010).

Em face dos inúmeros processos desempenhados pelas bactérias ureolíticas e de suas possíveis aplicações, o presente artigo propiciou uma revisão acerca dos principais mecanismos celulares envolvidos na precipitação do carbonato de cálcio por bactérias ureolíticas, bem como o detalhamento dos tipos de cristais produzidos e fontes de isolamento desses organismos. Há ainda uma ênfase especial nas aplicações desses organismos. Ressalta-se ainda que embora exista uma variedade de artigos sobre o assunto disponíveis nos bancos de dados de revistas acadêmicas e científicas, a maioria desse conteúdo encontra-se divulgado em inglês. Almeja-se a divulgação em português desse tema tão relevante e amplamente discutido.

\section{UREASES}

As ureases (ureia amidohidrolases, EC 3.5.1.5) são enzimas responsáveis pela hidrólise da ureia. Foram isoladas inicialmente na forma cristalina a partir da planta conhecida como feijão-de-porco (Canavalia ensiformis). Estão amplamente distribuídas na natureza e encontradas no solo e em ambientes aquáticos, estando presentes em plantas, algas, bactérias, fungos e invertebrados. Funcionalmente, as 
ureases fazem parte da superfamília das amidohidrolases e fosfotriesterases. Mesmo apresentando diferentes estruturas proteicas, as ureases exercem uma única função catalítica, a hidrólise da ureia, tendo como produtos finais a amônia e o ácido carbônico (AL-THAWADI, 2008; JIANG et al., 2016).

Uma importante característica das ureases é a presença de centros metálicos em seus sítios ativos, cuja função é ativar o substrato para que ocorra a reação. Essas enzimas são as únicas a possuírem íons de níquel nos sítios ativos dentre as outras da superfamília das metalohidrolases. Desde a descoberta, a urease tem sido intenso objeto de pesquisa, visando elucidar o seu papel e ocorrência na natureza, os mecanismos de funcionamento, a reação a compostos exógenos e a especificidade de ação. No solo, estas desempenham papel fundamental ao fornecer nitrogênio na forma de amônia aos organismos. Assim, esta função é essencial para promover o crescimento destes (KRAJEWSKA, 2009).

\section{MECANISMOS ENERGÉTICOS DE BACTÉRIAS UREOLÍTICAS}

Vários são os micro-organismos capazes de produzir ATP através da hidrólise da ureia (VON AHNEN et al., 2015). A força próton motriz ou potencial eletroquímico $(\Delta p)$ é que controla a geração da energia (Eq. 1). Por exemplo, em Sporosarcina pasteurii (anteriormente conhecida como Bacillus pasteurii) a produção de energia está vinculada a geração de ATP oriunda da hidrólise da ureia, principalmente com a produção do cátion $\mathrm{NH}_{4}^{+}$(AL-THAWADI, 2008).

$$
\Delta \mathrm{p}=\Delta \mathrm{pH}+\Delta \mathrm{w}(\mathrm{Eq} .1)
$$

$\mathrm{Na}$ equação, o gradiente de $\mathrm{pH}$, que é a diferença entre o $\mathrm{pH}$ no interior $\mathrm{e}$ exterior das células é representado por $\Delta \mathrm{pH}$ e $\Delta \mathrm{w}$ é o potencial da membrana ou carga do gradiente (AL-THAWADI, 2008). A geração de ATP em micro-organismos neutrófilos (organismos que crescem preferencialmente em $\mathrm{pH}$ neutro) depende da gradiente de concentração dos prótons. As células os liberam para o meio exterior através da cadeia de transporte de elétrons, gerando um acúmulo de prótons. Estes podem se mover para o interior da célula, dependendo do gradiente de concentração, através da enzima ATP-sintase. Tal mecanismo resulta na geração de ATP (PRESCOTT et al., 1993).

\section{O PAPEL DA UREASE NA PRECIPITAÇÃO MICROBIANA DE CARBONATO DE CÁLCIO}

A precipitação de carbonato de cálcio é um processo químico que é controlado por quatro fatores chave (JIANG et al., 2016):

(1) A concentração do carbono inorgânico dissolvido;

(2) a concentração dos íons cálcio;

(3) $\mathrm{o} \mathrm{pH}$; e

(4) a presença de sítios de nucleação.

$\mathrm{Na}$ precipitação de carbonato de cálcio por micro-organismos, os três primeiros fatores são a chave para a precipitação, sendo que o quarto fator não é crucial, pois as bactérias podem se comportar como sítios ativos de nucleação. A presença de vários grupos que apresentam cargas negativas na parede da célula, em $\mathrm{pH}$ neutro, podem fazer com que íons metálicos carregados positivamente se liguem às superfícies microbianas. Esses íons podem posteriormente, reagir com ânions para formar um sal insolúvel. O ânion desse sistema pode ser de origem microbiana (produto do próprio metabolismo), ou pode ter advindo de origem 
abiótica. Em caso de excesso suficiente de cátions e ânions, o sal metálico ainda é responsável por iniciar a formação de mineral na superfície celular, atuando como um sítio de nucleação (AL-THAWADI, 2008).

Há duas vias metabólicas para a formação bacteriana de carbonatos: autotrófico e heterotrófico. Na primeira, o dióxido de carbono é utilizado como fonte de carbono, provocando a redução no ambiente bacteriano. Na presença de íons de $\mathrm{Ca}^{2+}$, a depleção resulta no aumento da produção de carbonato de cálcio. Em relação à via heterotrófica, os micro-organismos podem formar carbonato através da precipitação ativa ou passiva. No processo de precipitação ativa, a produção de íons carbonato ocorre devido à troca iônica através da bomba iônica de cálcio ou de magnésio. Já durante a precipitação passiva, a produção do íon carbonato ocorre devido à amonificação de aminoácidos, redução de nitratos ou pela degradação da ureia. Independentemente dos casos supracitados, a amônia é produzida como produto metabólito final, o que resulta no aumento do $\mathrm{pH}$ (AL-THAWADI, 2008).

A quantidade com que o carbonato de cálcio precipita, é em geral, uma função linear resultante do produto da concentração de íons de $\mathrm{Ca}^{2+} \mathrm{e} \mathrm{CO}_{3}{ }^{2-}$. Sendo assim, obedece-se a cinética das reações, caso um dos reagentes estiver em excesso (ACHAL et al., 2015). As bactérias exercem papel fundamental ao influenciarem a saturação atingível e a taxa de precipitação de carbonato de cálcio, regulando a morfologia dos cristais formados. Quando a concentração destes íons excede o produto de solubilidade (Kps), a solução do meio torna-se supersaturada. Quanto mais supersaturada for a solução, maior é a chance de a precipitação de carbonato de cálcio ocorrer (DHAMl et al., 2013a).

A urease ao hidrolisar a ureia, produz amônia e carbamato (Eq. 2), que hidrolisam-se espontaneamente para produzir outra molécula de amônia e ácido carbônico (Eq. 3). Estes produtos equilibram-se em meio aquoso, formando bicarbonato e amônio, além de íons hidróxido (Eq. 4 e 5), que resultam na elevação do $\mathrm{pH}$. Esta alteração do $\mathrm{pH}$ pode alterar o equilíbrio do bicarbonato, gerando íons carbonato (Eq. 6), que na presença de íons solúveis de cálcio, precipitam como $\mathrm{CaCO}_{3}$ (Eq. 7) (DHAMl et al., 2013b). A Figura 3.1 esquematiza o processo de produção de carbonato de cálcio pela enzima urease.

$\mathrm{CO}\left(\mathrm{NH}_{2}\right)_{2}+\mathrm{H}_{2} \mathrm{O} \longrightarrow \mathrm{NH}_{2} \mathrm{COOH}+\mathrm{NH}_{3}$ (Eq. 2)

$\mathrm{NH}_{2} \mathrm{COOH}+\mathrm{H}_{2} \mathrm{O} \longrightarrow \mathrm{NH}_{3}+\mathrm{H}_{2} \mathrm{CO}_{3}$ (Eq. 3)

$\mathrm{H}_{2} \mathrm{CO}_{3} \longleftrightarrow \mathrm{HCO}_{3}^{-}+\mathrm{H}^{+}$(Eq. 4)

$2 \mathrm{NH}_{3}+2 \mathrm{H}_{2} \mathrm{O} \leftrightarrow 2 \mathrm{NH}_{4}^{+}+2 \mathrm{OH}^{-}$(Eq. 5)

$\mathrm{HCO}_{3}^{-}+\mathrm{H}^{+}+2 \mathrm{NH}_{4}^{+}+2 \mathrm{OH}^{-} \leftrightarrow \mathrm{CO}^{2-}{ }_{3}+2 \mathrm{NH}_{4}^{+}+2 \mathrm{H}_{2} \mathrm{O}$ (Eq. 6)

$\mathrm{CO}^{2-}{ }_{3}+\mathrm{Ca}^{2+} \leftrightarrow \mathrm{CaCO}_{3}\left(\mathrm{Kps}=3.8 \times 10^{-9}\right)$ (Eq. 7)

Às vezes, a parede celular bacteriana pode apresentar cargas negativas, e com isso, atrair cátions como $\mathrm{Ca}^{2+}$ para depositarem-se na superfície celular. O $\mathrm{Ca}^{2+}$ reage com os íons $\mathrm{CO}_{3}{ }^{2-}$ e precipitando carbonato de cálcio na superfície da parede celular, que leva à morte das bactérias (Eq. 8 e 9) (HELMI et al., 2016).

$\mathrm{Ca}^{2+}+$ Célula $\rightarrow$ Célula-Ca ${ }^{2+}$ (Eq. 8)

Célula- $\mathrm{Ca}^{2+}+\mathrm{CO}_{3}^{2-} \rightarrow$ Célula-CaCO${ }_{3}$ (Eq. 9) 


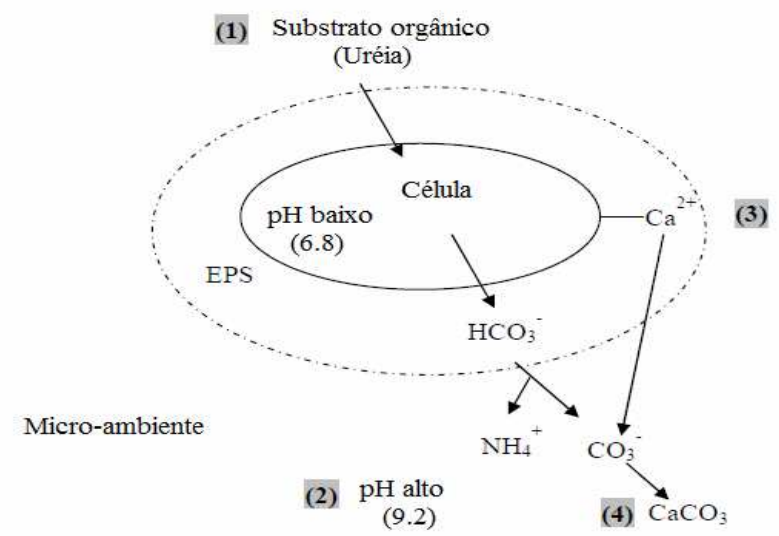

FIGURA 1: Modelo esquemático resumindo o papel da urease na precipitação $\mathrm{CaCO}_{3}$ mediada por micro-organismos: (1) hidrólise da ureia, (2) aumento da alcalinidade, (3) adsorção superficial de íons $\mathrm{Ca}^{2+}$ e (4) nucleação e crescimento do cristal. EPS significa substância polimérica extracelular (adaptado de AL-THAWADI, 2008).

\section{OS DIFERENTES POLIMORFOS DE CARBONATO DE CÁLCIO}

Diferentes tipos de polimorfos são formados a partir da biomineraliação tais como as fases anidras de carbonato de cálcio: calcita, aragonita e vaterita; bem como fases cristalinas hidratadas como a monohidrocalcilta, ikeita, e carbonato de cálcio amorfo (ACC) (DHAMl et al., 2013b; ANBU et al., 2016). Dentre estes, vaterita e calcita são os polimorfos de carbonato de cálcio bacterianos mais comuns. A vaterita é uma fase menor, metaestável e transitória durante a formação de calcita. A calcita é o polimorfo de $\mathrm{CaCO}_{3}$ mais termodinamicamente estável sendo o produto primário de $\mathrm{CaCO}_{3}$ em diversos MICPs (DHAMl et al., 2014; GANENDRA et al., 2014).

A precipitação de $\mathrm{CaCO}_{3}$ por mistura concentrada dos íons $\mathrm{Ca}^{2+}$ e $\mathrm{CO}_{3}{ }^{2-}$ envolve pelo menos três etapas: formação de $\mathrm{CaCO}_{3}$ amorfo, que é uma forma de $\mathrm{CaCO}_{3}$ com baixa estabilidade e alta solubidade; transformação de $\mathrm{CaCO}_{3}$ amorfo em vaterita e transformação de vaterita termodinamicamente instável em calcita estável (DHAMI et al., 2013b). POUGET e colaboradores em 2009 propuseram um modelo controlado dos estágios iniciais da formação de $\mathrm{CaCO}_{3}$, ou seja, antes mesmo da transformação de ACC em vaterita e calcita. Nesses estágios iniciais a precipitação do $\mathrm{CaCO}_{3}$ começaria com a formação de clusters de pré-nucleação, agregação destes para formação de nanopartículas de ACC e associação destas nanopartículas com a superfície do molde para iniciar o crescimento do ACC.

A fonte de cálcio influencia na forma do cristal produzido. Diferentes fontes de cálcio induzem cristais com formas diferentes, sendo a forma romboédrica induzida pelo cloreto de cálcio a mais estável de $\mathrm{CaCO}_{3}$ (GOROSPE et al., 2013) Outras fontes de cálcio induzem a formação de diferentes formas de $\mathrm{CaCO}_{3} . \mathrm{O}$ acetato de cálcio, por exemplo, induz uma forma lamelar (uma forma metaestável de $\mathrm{CaCO}_{3}$ ) que é composta de vaterita, enquanto que o lactato de cálcio e glucanato de cálcio induzem uma forma de empacotamento mais complexa que leva ao crescimento de vaterita com uma forma esférica (RODRIGUEZ-NAVARRO et al., 2007).

Diferenças na atividade da urease específicas de cada cepa podem ser responsáveis por diferenças morfológicas na formação dos cristais. Essas diferenças 
podem interferir na proteína específica EPS, produzida por diferentes tipos de bactérias que controlam a seleção de polimorfos de calcita ou aragonita, tendo em vista que as proteínas EPS podem ligar-se ao $\mathrm{Ca}^{2+}$ e promover a precipitação de carbonatos (DHAMl et al., 2013b).

A composição do meio de cultura também pode afetar a morfologia, pois diferentes espécies bacterianas são capazes de precipitar diferentes formas, quantidades, e tamanhos de cristais de carbonato partindo do mesmo meio sintético. Vários pesquisadores têm utilizado diferentes tipos de fontes de cálcio para indução da precipitação de $\mathrm{CaCO}_{3}$, sendo que o cloreto de cálcio é uma das melhores para indução da precipitação (ACHAL ; PAN, 2014). Contudo, esta fonte de cálcio ao ser utilizada para melhorar as propriedades mecânicas ou reparar estruturas de argamassa e concreto pode apresentar efeito contrário, e promover patologias graves. A corrosão eletroquímica causada pelo ataque dos cloretos é uma das principais causas de deterioração das estruturas de concreto armado (CASCUDO, 1997).

\section{FATORES QUE AFETAM A EFICIÊNCIA DA MICP}

A quantidade de carbonato de cálcio precipitada e a atividade da urease são baseadas em diversos fatores ambientais, tais como, o tipo de bactéria, a concentração celular bacteriana, o pH, a temperatura, e a concentração de ureia e cálcio (SOON et al., 2014; AMARAKOON ; KAWASAKI, 2016; HELMI et al. 2016).

O tipo de bactéria é essencial para a capacidade de produção da enzima urease. Várias bactérias produtoras de urease têm sido estudadas tais como Aerobacter aerogenes, Bacillus megaterium, B. flexus, B. firmus, B. subtilis, $B$. cereus, Bacillus sp., B. thuringiensis, Pseudomonas azotoformans, Sporosarcina pasteurii, S. soil e Artrhobacter crystallopoietes (DHAMl et al., 2013c; GOROSPE et al., 2013; JAGADEESHA KUMAR et al., 2013; ACHAL ; PAN, 2014; KANG et al., 2014; NONAKARAN et al., 2015; YANG et al., 2016; ZHU et al., 2016).

Diferentes tipos de bactérias têm sido descritas como capazes de produzir diferentes quantidades de urease e carbonato de cálcio. Bactérias do gênero Bacillus são comumente utilizadas para precipitação de calcita através da ação da enzima urease. Por exemplo, B. megaterium tem sido utilizada para aumentar a força no concreto e melhorar a durabilidade de materiais de construção e estruturas (DHAMI et al., 2013c; SOON et al., 2013; KRISHNAPRIYA et al., 2015). Sporosarcina pasteurii é o principal micro-organismo utilizado em diversas aplicações tais como remediação de metais potencialmente tóxicos e radionucleotídeos, remediação de fissuras em concreto e melhoria das características de solo (DHAMI et al., 2013b; GOROSPE et al., 2013; LAUCHNOR et al., 2013; LI et al., 2013; GRABIEC et al., 2017).

Elevadas concentrações celulares bacterianas aumentam a quantidade de carbonato de cálcio precipitada por MICP, devido ao aumento da concentração de urease e da hidrólise da ureia (OKWADHA ; LI, 2010). A hidrólise da ureia tem uma relação direta com a concentração celular bacteriana. Stocks-Fischer e colaboradores (1999) demostraram que as células atuam como locais de nucleações para precipitação de $\mathrm{CaCO}_{3}$, sendo este um fator importante pra precipitação dos cristais. Neste estudo, os autores compararam a eficiência da precipitação microbiana de carbonato de cálcio com a precipitação química induzida e constataram que $98 \%$ da concentração inicial de $\mathrm{Ca}^{2+}$ foi precipitada microbiologicamente enquanto que apenas $35 \%$ e $54 \%$ foram precipitadas quimicamente em água e em meio de cultura, respectivamente. Esta diferença foi 
constatada porque as bactérias se portaram como sítio ativo de nucleação para o $\mathrm{CaCO}_{3}$ e criaram um ambiente alcalino propício para a formação e crescimento dos cristais.

A precipitação de $\mathrm{CaCO}_{3}$ é influenciada pelo $\mathrm{pH}$, pois a enzima urease apenas se ativará em faixas de $\mathrm{pH}$ específicas para que a hidrólise da ureia ocorra. Grande parte do $\mathrm{CaCO}_{3}$ precipitado ocorre em condições alcalinas, com pH variando entre 8,7 e 9,5 (STOCKS-FISCHER et al., 1999; HELMI et al., 2016), entretanto, MOBLEY et al., (1995) verificaram que o pH ótimo para a urease era quase neutro.

A hidrólise da ureia pela urease depende da temperatura, assim como em outras reações enzimáticas. A temperatura ótima para a maioria das ureases varia entre 20 a $37^{\circ} \mathrm{C}$ (OKWADHA ; LI, 2010; HELMI et al., 2016). DHAMI et al. (2014) constataram que a enzima urease é completamente estável a $35^{\circ} \mathrm{C}$, mas quando a temperatura é aumentada para $55^{\circ} \mathrm{C}$ a atividade da enzima cai cerca de $47 \%$.

A hidrólise da ureia pela enzima urease não só apenas eleva o pH do meio como também libera nitrogênio que pode ser utilizado como fonte de energia (ACHAL \& PAN, 2014). Isso ocorre porque o micro-organismo pode produzir amônia como produto da hidrólise enzimática da ureia, criando um ambiente alcalino no entorno celular, elevando o $\mathrm{pH}$ e consequentemente induzindo a precipitação de $\mathrm{CaCO}_{3}$ (STOCKS-FISCHER et al., 1999). A concentração da fonte de cálcio e de ureia é importante para a precipitação. Altas concentrações destes componentes diminuem a eficiência na precipitação de calcita, enquanto que a eficiência é aumentada em baixas concentrações (0,05 - 0,25 M) (OKWADHA ; LI, 2010).

\section{FONTES DE ISOLAMENTO DE BACTÉRIAS UREOLÍTICAS}

O principal objetivo de MICP é o isolamento e seleção de potentes bactérias produtoras de urease. Para realizar a precipitação de carbonato de cálcio pela via da hidrólise da urease o micro-organismo deve produzir uma quantidade suficiente desta enzima. Deste modo, vários pesquisadores têm isolado micro-organismos ureolíticos de várias fontes (ACHAL ; PAN, 2014; KANG et al., 2014; GARCíA et al., 2016). Estes micro-organismos podem induzir a precipitação de $\mathrm{CaCO}_{3}$ e têm sido estudados para diversas aplicações como remediação, consolidação e cimentação (DE MUYNCK et al. 2008; PHILLIPS et al., 2013).

Garcia et al. (2016) isolaram cepas capazes de precipitar $\mathrm{CaCO}_{3}$ a partir de amostras de depósitos calcários e águas de gotejamento de duas minas da Colômbia. Em estudo realizado por Kim e Youn (2016) bactérias ureolíticas dos gêneros Bacillus, Sporosarcina e Staphylococcus aptas a precipitar $\mathrm{CaCO}_{3}$ foram isoladas a partir de amostras oriundas de solos de areia calcária e solos de caverna calcária, de duas cidades da Coreia do Sul. Krishnapriya et al. (2015) isolaram bactérias ureolíticas do gênero Bacillus precipitadoras de $\mathrm{CaCO}_{3}$ a partir de amostras de solo de uma fábrica de cimento localizada em Tamil Nadu, Índia. Bactérias ureolíticas que precipitam $\mathrm{CaCO}_{3}$ utilizadas para melhorar a força compressiva em argamassa foram isoladas a partir de amostras de estruturas de concreto em estudo realizado por Park et al. (2010).

A bactéria produtora de urease Bacillus sp. CR2 foi isolada a partir de amostras de solo de uma mina de Xinjiang, China (ACHAL \& PAN, 2014) e diversas espécies do gênero Sporosarcina foram isoladas a partir de amostras do solo de um viveiro na Universidade de Tsinghwa, China (LI et al., 2013). Cepas positivas foram identificadas através da coloração rosa formada pela hidrólise da ureia em placas de água para teste de ureia. 


\title{
APLICAÇÕES DA BIOPRECIPITAÇÃO DE CARBONATO DE CÁLCIO POR BACTÉRIAS UREOLITICAS
}

\author{
O processo de MICP é uma técnica
}

efetiva e ambientalmente "amigável" que pode ser aplicada para resolver diversos problemas ambientais, incluindo a remediação de íons cálcio, radionucleotídeos e metais potencialmente tóxicos, sequestro de $\mathrm{CO}_{2}$, restauração de calcário em prédios históricos, bio-estabilização de solos e taludes, biocimentação, proteção da superfície de argamassas e concreto, remediação de fissuras dentre outras aplicações (LE METAYER-LEVREL et al., 1999; AL-THAWADI, 2008; DE MUYNCK et al., 2010; PHILLIPS et al., 2012; ABO-EL-ENEIN et al., 2013).

\section{REMOÇÃO DE CONTAMINANTES Remoção de íons de $\mathrm{Ca}^{2+}$}

Hammes et al. (2003) avaliaram o potencial de remoção de $\mathrm{Ca}^{2+}$ de águas residuais de indústria através da MICP por degradação bacteriana de ureia. Elevadas concentrações destes íons presentes em águas residuais geram severos problemas de operação, com várias implicações econômicas, como incrustação em reatores e encanamentos, resultado da precipitação do cálcio como gipsita, fosfato e/ou carbonato. Até $90 \%$ dos íons de cálcio presentes na água examinada foram removidos com a adição de uma baixa concentração de ureia $\left(0-16 \mathrm{~g} \cdot \mathrm{L}^{-1}\right)$.

\section{Remoção de radionucleotídeos}

Nos organismos vivos, o estrôncio é altamente tóxico e solúvel e, portanto, pode ser facilmente passado através da cadeia alimentar a partir do solo ou água contaminados (SHARMA et al., 2015). Os efeitos carcinogênicos e a mobilidade do estrôncio afetam a usabilidade da água subterrânea e as técnicas convencionais para remediação são caras e ineficazes (LAUCHNOR et al., 2013). A captura de radionucleotídeos divalentes de estrôncio $90\left({ }^{90} \mathrm{Sr}^{2+}\right)$ via MICP em águas subterrâneas após adição de altas concentrações de ureia e baixa concentração de íns $\mathrm{Ca}^{2+}$ foi investigada por Fujita et al. (2004) e Brookshaw et al. (2012). Formouse carbonato de estrôncio $\left({ }^{90} \mathrm{SrCO}_{3}\right)$, e com isso verificou-se que os íons de ${ }^{90} \mathrm{Sr}^{2+}$ substituem os íons de $\mathrm{Ca}^{2+}$ nos cristais de carbonato, prevenindo o espalhamento da contaminação por este radionucleotídeo.

Achal et al. (2012) analisaram o potencial de remoção de estrôncio (Sr) de areias quartzíticas através do MICP. Os autores demonstraram neste estudo que a bactéria Halomonas sp., removeu cerca de $80 \%$ do $\mathrm{Sr}$ das amostras de areia avaliadas. Além disso, demonstrou-se que a MICP sequestra estrôncio solúvel como biomineral e poderia ser utilizado como um biorremediador importante do $\mathrm{Sr}$, do ponto de vista ecológico e ambiental.

\section{Remoção de metais potencialmente tóxicos}

Metais potencialmente tóxicos comuns tais como: cádmio, crômio, cobalto, cobre, arsênio, chumbo, mercúrio entre outros têm ocorrência natural, mas concentram-se devido as atividades antropogênicas (MANI ; KUMAR, 2014; SINGH ; PRASAD, 2015). Os tratamentos químicos e físicos convencionais tais como precipitação, adsorção, tratamento eletroquímico, técnica de evaporação, filtragem, troca iônica, oxidação/redução e osmose reversa são utilizados para remoção desses metais em ambientes contaminados. Esses métodos tradicionais geralmente não removem totalmente os metais porque são ineficazes, caros e consomem grandes quantidades de produtos químicos e energia (GUPTA et al., 2015). 
Muitos tratamentos biológicos, utilizando micro-organismos, foram empregados para remover metais potencialmente tóxicos de locais contaminados através de fitorremediação, bioacumulação, biolixiviação, biossorventes e bioimobilização. Entretanto, estes métodos não são eficazes por serem demorados, dispendiosos e resultam na liberação de metais potencialmente tóxicos imobilizados ou adsorvidos para o meio ambiente (ACHAL et al., 2011).

Métodos alternativos como a MICP são necessários para remover os metais potencialmente tóxicos de forma efetiva, econômica e de um modo eco-amigável (HAMDAN et al. 2011). Vários autores têm constatado que a MICP apresenta potencial para remediação destes metais. Li et al. (2013) reportaram que várias espécies de Sporosarcina e $B$. lentus produtoras de urease são aptas para removerem 88 a $99 \%$ de metais potencialmente tóxicos após 48 horas de incubação. Achal e colaboradores (2011) isolaram a bactéria tolerante a cobre Kocuria flava CR1 a partir de uma mina na China, e obtiveram remoção de $97 \%$ de cobre do ambiente usando MICP. Achal et al. (2012) isolaram a bactéria tolerante a arsênio Sporosarcina ginsengisoli CR5 e reportaram uma remoção de 96,3\% do arsênio após sete dias de incubação.

\section{SEQUESTRO DE $\mathrm{CO}_{2}$}

O aquecimento global é uma questão ambiental importante que ocorre devido as concentrações crescentes de $\mathrm{CO}_{2}$ na atmosfera terrestre (MIGLIARDINI et al 2014). $\mathrm{O} \mathrm{CO}_{2}$ é removido primariamente da atmosfera via fotossíntese realizada por plantas e organismos marinhos e retorna para a atmosfera através da respiração de organismos quimiorganotróficos e animais. Na natureza, o sequestro de $\mathrm{CO}_{2}$ por fixação química na forma de carbonato como calcita, aragonita, magnesita e dolomita é muito lenta (MANN, 2001). A MICP é um método efetivo para remoção de $\mathrm{CO}_{2}$ do meio ambiente (PHILLIPS et al. 2012). Neste caso, o $\mathrm{CO}_{2}$ é convertido em minerais de carbonato que podem formar diferentes cristais como calcita, vaterita, aragonita, dolomita e magnesita.

\section{AGENTE DE AGREGAÇÃO EM RESERVATÓRIOS}

A MICP pode ser utilizada também como agente de agregação em reservatórios de petróleo. Leonard (1986) mostrou que células bacterianas foram capazes de vedar rochas altamente permeáveis de reservatórios de petróleo. Valores entre 8 e $30 \%$ do óleo do reservatório foram recuperados do método comum de produção de petróleo.

Tratamentos primário e secundário por injeção de água são utilizados para recuperação de óleo cru nos poros da rocha do reservatório de petróleo. Tais métodos não são tão eficientes, pois levaram a uma retenção de $67 \%$ do total de óleo nos poros da rocha reservatório. Sendo assim, existiu o interesse no uso de micro-organismos com objetivo de aumentar o aproveitamento do óleo, que pode ser alcançada pela produção microbiana de biopolímeros e biosurfactantes na superfície; crescimento microbiano nos poros das rochas reservatório, produzindo gases, surfactantes e outras substâncias químicas; ou por agregação microbiana dos poros nos canais do reservatório (AL-THAWADI, 2008).

As rochas do reservatório apresentam zonas com alta permeabilidade. Quando há a injeção da água para deslocar o óleo, esta se move por entre os poros da zona de alta permeabilidade, desviando elevada quantidade de óleo. Por apresentar um pequeno tamanho, as bactérias são capazes de transitar até regiões altamente permeáveis, vedando os poros por agregação, e consequentemente, a ENCICLOPÉDIA BIOSFERA, Centro Científico Conhecer - Goiânia, v.14 n.26; p.868 2017 
recuperação de óleo e eficiência de arraste, são aumentadas em até 100\% (BRYANT, 1987).

\section{RESTAURAÇÃO DE PRÉDIOS HISTÓRICOS}

A MICP foi utilizada em experimento realizado na cidade francesa de Thouars, para o tratamento da torre de uma igreja do século XII feita de rocha calcária. Le-Metayer-levrel e colaboradores (1999) validaram a viabilidade do processo microbiano na restauração do calcário da superfície tratada. A proteção superficial da rocha foi promovida pelo carbonato de cálcio produzido pelos microorganismos, reduzindo a absorção de água, sem alterar a aparência estética. Além disso, foi constatado que 0 desenvolvimento abundante de bactérias carbonatogênicas preveniu o a formação de consórcios de bactérias acidificadoras.

\section{BIO-ESTABILIZAÇÃO DE SOLOS E TALUDES}

Vários são os grupos no mundo desenvolvendo estudos a fim de determinar métodos que beneficiam as propriedades mecânicas do solo como a rigidez, a resistência e a permeabilidade, prevenindo ou estabilizando erosões (KHODADADI ; BILSEL, 2012; JIANG ; SOGA, 2016). A maioria dos resultados e mais satisfatórios foram obtidos por estimulação dos micro-organismos naturais presentes no solo (LÓPEZ, 2008). A bio-estabilização de solos equivale na melhoria das propriedades geotécnicas destes mediante a precipitação de carbonato de cálcio (GÓMEZMUÑETÓN, 2009).

A compatibilidade morfológica entre os micro-organismos (tanto externos quanto nativos) e o solo no qual são injetados é um ponto importante a ser destacado na estabilização de solos. O tamanho relativamente pequeno dos microorganismos é vantajoso nesse ponto. As partículas do solo estão dispostas em uma vasta gama de tamanhos, apresentando primariamente entre "finas" e "grossas". Sendo assim, os micro-organismos são capazes de intermear através dos vários tipos de solo (HAMDAN et al. 2017).

Tendo em vista que é natural a presença de bactérias ureolíticas e ureia em solo, e sendo conhecido que esses micro-organismos são capazes de produzir $\mathrm{CaCO}_{3}$ por meio da degradação da ureia, essas bactérias são as mais estudadas para utilização em processos de bio-estabilização. Os cristais de carbonato são formados ao redor das células bacterianas, interligando-se com as partículas do solo, o que gera uma resistência ao cisalhamento (tensão cortante) (REDDY, 2013).

\section{BIOCIMENTO OU BIOCONCRETO}

O cimento é amplamente utilizado como um material de construção (STABNIKOV et al. 2013). Entretanto, a produção gera impactos ambientais durante todas as etapas da fabricação. Somado a este fato, a produção de cimento mundial é responsável pelo consumo de cerca de $10-15 \%$ da energia industrial total e $5-8 \%$ da emissão antropogênica de $\mathrm{CO}_{2}$ (USON et al. 2013; GONZÁLEZ-KUNZ et al. 2017). O biocimento é uma alternativa ao cimento (DE MUYNK et al. 2010) que pode produzir materiais aglutinantes por meio do tratamento com MICP para melhorar a resistência e durabilidade de materiais cimentícios (PHILLIPS et al. 2013; DHAMI et al. 2014).

$\mathrm{Na}$ área de construção civil a MICP é empregada principalmente em duas formas: como material de cimentação ou como uma camada de proteção superficial. Enquanto o primeiro é chamado de biocimentação o último é chamado de biodeposição (ACHAL ; MUKHERJEE, 2015). O "biocimento" é produto da MICP 
que visa diminuir ou eliminar os espaços entre as partículas de um material granular (areia como um agregado, por exemplo). Para atingir esse objetivo, utiliza-se um meio líquido contendo bactérias, ureia como uma solução de substrato e íons de cálcio. A enzima urease, produzida pela bactéria, hidrolisa a ureia que juntamente com os íons de cálcio são utilizados como base para formar o "biocimento". O cimento une os grãos, criando uma massa sólida (ACHAL et al., 2014).

$A$ biocimentação está diretamente relacionada à atividade enzimática da cepa bacteriana e da composição do meio de cultura utilizado. Dessa forma, quanto mais elevada a atividade da urease e melhor o perfil nutricional do meio, maior é a capacidade de precipitação de carbonato de cálcio (PACHECO-TORGAL ; LABRINCHA, 2013). Este processo tem demonstrado ser eficaz na ligação de grãos de areia para fazer bio-arenitos capazes de resistir a compressão. A biocimentação também é utilizada para a melhoria da resistência à compressão de outros materiais constituídos de cimento (CHENG et al., 2016).

A areia é o material mais comumente utilizado como agregado para fabricação de materiais de construção e estruturas. Muitos são os estudos perante os quais se associaram com sucesso a MICP à cimentação da areia. Em estudos realizados por Achal e colaboradores (2009), a biocimentação foi usada em conjunto com cimento convencional para fazer argamassas. As células bacterianas cultivadas em meio líquido foram adicionadas na mistura de areia e cimento, e corpos de provas de $70.6 \mathrm{~mm}$ foram moldados. Tais amostras de cimento mostraram um aumento de $17-36 \%$ da resistência à compressão, enquanto a resistência à permeabilidade à água fora aumentada quatro vezes.

\section{PROTEÇÃO DA SUPERFÍCIE DE ARGAMASSAS E CONCRETO VIA BIODEPOSIÇÃO}

Elementos e materiais de construção como estruturas de concreto e argamassa estão suscetíveis à ação do intemperismo de vários fatores químicos, físicos e biológicos (LE-METAYER-LEVREL et al. 1999). Devido a sua composição, rochas carbonáticas estão sujeitas ao intemperismo. O avanço progressivo da dissolução da matriz mineral como consequência do intemperismo leva ao aumento da porosidade, e consequentemente, a uma redução das características mecânicas. (DE MUYNCK et al. 2010). Assim sendo, com o objetivo de diminuir a suscetibilidade a deterioração, vários tratamentos de conservação têm sido empregados para alterar algumas características das rochas, protegendo-as de ações intempéries, como em ambientes com altas concentrações de sulfato (NOUSOUHIAN et al., 2015). Repelentes de água têm sido aplicados para proteger as rochas do acesso de água e de agentes agressivos presentes na atmosfera. O uso de consolidantes para rocha visa o reestabelecimento da coesão entre os grãos deteriorados da mesma. Contudo, ambos os tratamentos de conservação estão sujeitos a frequente controvérsia devido a ação não reversível e a atuação limitada, podendo até contribuir para acelerar a deterioração de rochas (DE MUYNCK et al. 2010).

$\mathrm{Na}$ biodeposição, uma camada de carbonato de origem microbiológica é precipitada sobre um substrato poroso, tal como tijolo, cimento ou argamassa. A MICP pode depositar os cristais formados de carbonato dentro dos poros da superfície e evitar a entrada de materiais nocivos para o substrato. Assim, a superfície de materiais porosos, tais como de tijolos, concretos e pedra calcária, pode ser protegida da ação da água ou da invasão química (ação de cloretos e sulfatos, por exemplo) (PHILLIPS et al., 2013). A biodeposição envolve vários microorganismos, caminhos e ambientes a qual pode ser obtida através da exposição da 
superfície à cultura de bactérias ureolíticas. A exposição pode ser feita por imersão ou pulverização (DE MUYNCK et al., 2008).

Dick et al. (2006) utilizaram a biodeposição no tratamento e restauração de estruturas degradadas. Nos seus experimentos, cubos de $30 \mathrm{~mm}$ foram incubados em jarras esterilizadas com meio líquido contendo ureia e fonte de cálcio. Várias camadas de calcita foram depositadas sobre o calcário degradado durante quatro semanas. Concluíram que a melhor biodeposição homogênea de calcita em cubos de calcário fora obtida pela bactéria com maior eficiência ureolítica. Depois, uma tentativa bem sucedida foi feita para melhorar a eficiência do processo em biodeposição de calcário baseado na influência de parâmetros químicos, ou seja, a concentração de sais de cálcio e de ureia. O aumento das concentrações desses constituintes em certo nível e a repetição do tratamento melhorou a resistência do calcário em absorver água, devido a MICP. Além disso, os corpos de prova tratados por biodeposição apresentaram aumento da resistência frente a sonicação.

A MICP tem sido proposta como um método eco-amigável para proteger rochas ornamentais deterioradas (LE METAYER-LEVREL et al., 1999) e como um método de melhoramento da durabilidade de materiais cimentícios (RAMACHANDRAN et al., 2001). Ivanov et al. (2015) em experimentos com Bacillus sphaericus crescidos em meio com ureia, constataram a biodeposição com este micro-organismo como um tratamento para superfícies de materiais cimentícios com diferentes porosidades. Os autores demonstraram que o tratamento resultou em aumento da resistência de corpos de prova de argamassa contra carbonação, penetração de cloretos, congelamento e descongelamento, especialmente para argamassas mais porosas.

\section{REMEDIAÇÃO DE FISSURAS}

Com intuito de estabelecer uma alternativa sustentável e rentável, a MICP tem sido estudada para aplicação em cicatrização de fissuras em concreto (SHARMA et al., 2017). Zhong e Islam (1995) utilizaram a consolidação de misturas de areia, compostas por bactérias, nutrientes e um material de preenchimento para remediação de rachaduras em granito. Dentre os diferentes materiais avaliados nas misturas, os granitos que foram tratados com Sporosarcina pasteurii, sílica ativa $(10 \%)$ e areia (90\%) mostraram aumento à força compressiva e a redução da permeabilidade.

Em estudo sobre remediação em concreto com $S$. pasteurii, Ramachandran et al., (2001) constataram que a precipitação bacteriana de $\mathrm{CaCO}_{3}$ era muito efetiva na remediação de rachaduras nesse elemento, aumentando a resistência à compressão em cubos de argamassa com rachaduras. Entretanto, a remediação microbiana foi mais efetiva em rachaduras superficiais do que nas mais profundas devido ao fato de $S$. pasteurii ser um organismo que cresce mais ativamente na presença de $\mathrm{O}_{2}$. De Belie e De Muynck (2009), em estudo semelhante, avaliaram a capacidade de $B$. sphaericus em reparar fissuras em concreto através da precipitação de carbonato de cálcio pela via de hidrólise da ureia. Observaram que cristais de $\mathrm{CaCO}_{3}$ formaram no interior dos poros do material estudado, selando a rachadura. Um dos resultados desse efeito foi o decréscimo da permeabilidade a água.

\section{LIMITAÇÕES DA MICP}

Apesar do elevado potencial de aplicações da MICP em diversos campos, esta tecnologia apresenta algumas limitações no uso que devem ser superadas 
antes que possa ser amplamente aplicada em escala comercial. Uma desvantagem da MICP é que este trata-se de um processo microbiano normalmente lento e mais complexo do que os processos químicos. Isso ocorre porque a atividade do microorganismo depende de fatores ambientais como $\mathrm{pH}$, temperatura, concentração e difusão de nutrientes e metabólitos (IVANOV et al., 2015).

Outra desvantagem é que a MICP pode não ser ambientalmente "amigável" por completo. $\mathrm{O}$ amônio, que é formado durante o processo de hidrólise da ureia, em altas concentrações pode ser tóxico e perigoso para a saúde humana e microorganismos do solo. Este composto quando presente dentro de materiais de construção pode ser nitrificado em ácido nítrico por bactérias. O ácido nítrico, por sua vez, pode reagir com a calcita e formar nitrato de cálcio, que é um componente altamente solúvel que contribui para a biodeterioração de materiais de construção (GANENDRA et al., 2014).

Limitações econômicas como o uso de nutrientes de laboratório em aplicações de campo devem ser superadas. Para isso, é necessária a identificação de fontes de nutrientes alternativas e mais baratas para a MICP. Por exemplo, o líquido do macerado de milho pode oferecer fontes de nutrientes menos dispendiosas para uma comercialização com mais chances de ser sucedida (DHAMI et al., 2013b; PHILLIPS et al., 2013). Se comparada aos métodos tradicionais, a produção de grandes volumes de culturas e reagentes torna a MICP economicamente desafiadora. Desta forma, são necessárias pesquisas adicionais para melhorar a tecnologia de produção e reduzir os subprodutos indesejáveis para permitir o uso de MICP em escala comercial.

\section{CONSIDERAÇÕES FINAIS}

Diversos micro-organismos capazes de produzir a urease podem ser utilizados para a precipitação de carbonato de cálcio. Vários pesquisadores têm buscado desenvolver métodos para remoção de contaminantes na natureza. Contudo, estes métodos têm se mostrado ineficazes e caros. A MICP tem surgido como uma alternativa eficaz e ambientalmente correta para a remediação ambiental de metais potencialmente tóxicos e radionucleotídeos, por exemplo. Esta mesma técnica pode ser utilizada para melhorar as propriedades mecânicas de solos, de estruturas de argamassa e de concreto, bem como na reparação de fissuras e na proteção das superfícies destes elementos frente a ataques de agentes nocivos. As aplicações da MICP são ilimitadas e utéis em aplicações que visam gerar produtos seguros e ambientalmente estáveis. Mesmo que a MICP tenha vantagens, são necessários estudos mais aprofundados para superar as limitações antes da comercialização em escala industrial.

\section{REFERÊNCIAS}

ABO-EL-ENEIN, S. A.; ALI, A. H.; FATMA, N. T.; ABDEL-GAWWAD, H. A. Application of microbial biocementation to improve the physico-mechanical properties of cement mortar. HBRC Journal, v. 9, n. 1, p. 36-40, 2013. Disponível em: <http://dx.doi.org/10.1016/j.hbrcj.2012.10.004>. doi: 10.1016/j.hbrcj.2012.10.004

ACHAL, V.; MUKHERJEE, P. C.; BASU, M.; REDDY, S. Strain improvement of Sporosarcina pasteurii for enhanced urease and calcite production. Journal of Industrial Microbiology \& Biotechnology, v. 36, n. 7, p. 981-988, 2009. Disponível em: <http://dx.doi.org/10.1007/s10295-009-0578-z>. doi: 10.1007/s10295-0090578-z 
ACHAL, V.; PAN, X.; ZHANG, D. Remediation of copper-contaminated soil by Kocuria flava CR1, based on microbially induced calcite precipitation. Ecological Engineering, v. 37, n. 10, p. 1601-1605, 2011. Disponível em: <http://dx.doi.org/10.1016/j.ecoleng.2011.06.008>.

10.1016/j.ecoleng.2011.06.008

ACHAL, V.; XIANGLIANG, P.; ZHANG, D.; FU, Q. Bioremediation of Pbcontaminated soil based on microbially induced calcite precipitation. Journal of Microbiology and Biotechnology, v. 22, n. 2, p. 244-247, 2012. Disponível em: <http://dx.doi.org/10.4014/jmb.1108.08033>. doi: 10.4014/jmb.1108.08033

ACHAL, V.; LI, M.; ZHANG, Q. Biocement, recent research in construction engineering: status of China against rest of world. Advances in Cement Research, v. 26, n. 5, p. 281-291, 2014. Disponível em: <http://dx.doi.org/10.1680/adcr.13.00044>. doi: 10.1680/adcr.13.00044

ACHAL, V.; PAN, X. Influence of calcium sources on microbially induced calcium carbonate precipitation by Bacillus sp. CR2. Applied Biochemistry and Biotechnology, v. 173, n. 1, p. 307-317, 2014. Disponível em: <http://dx.doi.ogr/10.1007/s12010-014-0842-1 >. doi: 10.1007/s12010-014-0842-1

ACHAL, V.; MUKHERJEE, A. A review of microbial precipitation for sustainable construction. Construction and Building Materials, v. 93, p. 1224-1235, 2015. Disponível em: <http://dx.doi.org/10.1016/j.conbuildmat.2015.04.051>. doi: 10.1016/j.conbuildmat.2015.04.051

ACHAL, V.; MUKHERJEE, A.; KUMARI, D.; ZHANG, Q. Biomineralization for sustainable construction-A review of processes and applications. Earth-Science Reviews, v. 148, p. 1-17, 2015. Disponível em: <http://dx.doi.org/10.1016/j.earscirev.2015.05.008>. doi: 10.1016/j.earscirev.2015.05.008

AL-THAWADI, S. High strength in situ biocementation of soil by calcite precipitating locally isolated ureolytic bacteria. Murdoch University. Diss, 2008. Disponível em: $<$ http://researchrepository.murdoch.edu.au/id/eprint/721/>.

AMARAKOON, G. G. N. N.; KAWASAKI, S. Factors Affecting the Improvement of Sand Properties Treated with Microbially-Induced Calcite Precipitation. In: GeoChicago, p. 72-83, 2016. Disponível em: <http://dx.doi.org/10.1061/9780784480120.009>. doi: 10.1061/9780784480120.009

ANBU, P.; KANG, C. H.; SHIN, J. Y.; SO, J.S. Formations of calcium carbonate minerals by bacteria and its multiple applications. SpringerPlus, v. 5, n. 1, p. 250, 2016. Disponível em: <http://dx.doi.org/ 10.1186/s40064-016-1869-2>. doi: 10.1186/s40064-016-1869-2

BHADURI, S.; MITRA, S. K.; KUMAR, A. Understanding Biofilm Growth Dynamics Within a Stagnant Culture of Sporosarcina Pasteurii. Em: ASME 2014 International 
Mechanical Engineering Congress and Exposition. American Society of Mechanical Engineers, 2014. Disponível em: <http://dx.doi.org/10.1115/IMECE201436778 > doi: 10.1115/IMECE2014-36778

BONTOGNALI, T. R. R.; MCKENZIE, J. A.; WARTHMANN, R. J. Microbially influenced formation of $\mathrm{Mg}$-calcite and Ca-dolomite in the presence of exopolymeric substances produced by sulphate-reducing bacteria. Terra Nova, v. 26, n. 1, p. $72-$ 77, 2014. Disponível em: <http://dx.doi.org/10.1111/ter.12072>. doi: 10.1111/ter.12072

BROOKSHAW, D. R.; PATTRICK, R. A. D.; LLOYD, J. R.; VAUGHAN, D, J. Microbial effects on mineral-radionuclide interactions and radionuclide solid-phase capture processes. Mineralogical Magazine, v. 76, n. 3, p. 777-806, 2012. Disponível em: <https://doi.org/10.1180/minmag.2012.076.3.25>. doi: 10.1180/minmag.2012.076.3.25

BRYANT, R. S. Potential uses of microorganisms in petroleum recovery technology. In: Proceedings of the Oklahoma Academy of Science, p. 97-104, 1987. Disponível em: < http://digital.library.okstate.edu/oAs/oas_pdf/v67/p105_107.pdf>.

CASCUDO, O. O controle da corrosão de armaduras em concreto: inspeção e técnicas eletroquímicas. Pini, 1997.

CHENG, L.; SHAHIN, M. A.; CORD-RUWISCH, R. Surface percolation for soil improvement by biocementation utilizing in situ enriched indigenous aerobic and anaerobic ureolytic soil microorganisms. Geomicrobiology Journal, p. 1-11, 2016. Disponível em: <http://dx.doi.org/10.1080/01490451.2016.1232766 >. doi: 10.1080/01490451.2016.1232766

CUNNINGHAM, A. B.; LAUCHNOR, E.; ELDRING, J.; ESPOSITO, R.; MITCHELL, A. C.; GERLACH, R.; PHILLIPS, A. J.; EBIGBO, A.; SPANGLER, L. H. Abandoned well $\mathrm{CO} 2$ leakage mitigation using biologically induced mineralization: current progress and future directions. Greenhouse Gases: Science and Technology, v. 3, n. 1, p. 40-49, 2013. Disponível em: <http://dx.doi.org/10.1002/ghg.1331>. doi: 10.1002/ghg.1331

DE BELIE, N.; DE MUYNCK, W. Concrete repair, rehabilitation and retrofitting II. In: Alexander et al. (Eds.), Crack repair in concrete using biodeposition. Taylor \& Francis Group, London, pp. 291-292, 2009.

DE MUYNCK, W.; DE BELIE, N.; VERSTRAETE, W. Microbial carbonate precipitation in construction materials: a review. Ecological Engineering, v. 36, n. 2, p. 118-136, 2010. Disponível em: <http://dx.doi.org/10.1016/j.ecoleng.2009.02.006>. doi: 10.1016/j.ecoleng.2009.02.006

DE MUYNCK, W.; DEBROUWER, D.; DE BELIE, N.; VERSTRAETE, W. Bacterial carbonate precipitation improves the durability of cementitious materials. Cement and concrete Research, v. 38, n. 7, p. 1005-1014, 2008. Disponível em < http://dx.doi.org/10.1016/j.cemconres.2008.03.005>.

doi: 10.1016/j.cemconres.2008.03.005 
DE NOOIJER, L. J.; SPERO, H. J.; EREZ, J.; REICHART, G. J. Biomineralization in perforate foraminifera. Earth-Science Reviews, v. 135, p. 48-58, 2014. Disponível em: < http://dx.doi.org/10.1016/j.earscirev.2014.03.013>. doi: 10.1016/j.earscirev.2014.03.013

DHAMI, N. K.; REDDY, M. S.; MUKHERJEE, A. Biomineralization of calcium carbonate polymorphs by the bacterial strains isolated from calcareous sites. Journal of Microbiology and Biotechnology v. 23, n. 5, p. 707-714, 2013a. Disponível em: <http://dx.doi.org/10.4014/jmb.1212.11087>. doi: 10.4014/jmb.1212.11087

DHAMI, N. K.; REDDY, M. S.; MURKHERJEE, A. Biomineralization of calcium carbonates and their engineered applications: a review. Frontiers in microbiology, v. 4, p. 314, 2013b. Disponível em: <https://doi.org/10.3389/fmicb.2013.00314>. doi: 10.3389/fmicb.2013.00314

DHAMI, N. K.; REDDY, M. S.; MUKHERJEE, A. Bacillus megaterium mediated mineralization of calcium carbonate as biogenic surface treatment of green building materials. World Journal of Microbiology and Biotechnology, v. 29, n. 12, p. 2397-2406, 2013c. Disponível em: <http://dx.doi.org/10.1007/s11274-013-1408-z>. doi: $10.1007 / \mathrm{s} 11274-013-1408-z$

DHAMI, N. K.; REDDY, M. S.; MUKHERJEE, A, Synergistic role of bacterial urease and carbonic anhydrase in carbonate mineralization. Applied biochemistry and biotechnology, v. 172, n. 5, p. 2552-2561, 2014. Disponível em: <http://dx.doi.org/10.1007/s12010-013-0694-0>. doi: 10.1007/s12010-013-0694-0

DICK, J.; DE WINDT, W.; DE GRAEF, B.; SAVEYN, H.; DER MEEREN, P. V.; DE BELIE, N.; VERSTRAETE, W. Bio-deposition of a calcium carbonate layer on degraded limestone by Bacillus species. Biodegradation, v. 17, n. 4, p. 357-367, 2006. Disponível em: <http://dx.doi.org/10.1007/s10532-005-9006-x>. doi: $10.1007 / \mathrm{s} 10532-005-9006-x$

FUJITA, Y.; REDDEN, G. D.; INGRAM, J. C.; CORTEZ, M. M.; FERRIS, F. G.; SMITH, R. W. Strontium incorporation into calcite generated by bacterial ureolysis. Geochimica et Cosmochimica Acta, v. 68, n. 15, p. 3261-3270, 2004. Disponível em: <http://dx.doi.org/10.1016/j.gca.2003.12.018>. doi: http://dx.doi.org/10.1016/j.gca.2003.12.018

GANENDRA, G.; DE MUYNCK, W.; HO, A.; ARVANITI, E. C.; HOSSEINKHANI, B.; RAMOS, J. A. RAHIER, H. BOON, N. Formate oxidation-driven calcium carbonate precipitation by Methylocystis parvus OBBP. Applied and environmental microbiology, v. 80 , n. 15, p. 4659-4667, 2014. Disponível em: <http://dx.doi.org/10.1128/AEM.01349-14>. doi: 10.1128/AEM.01349-14

GARCÍA, M. G.; MÁRQUEZ, G. M. A.; MORENO, H. C. X. Characterization of bacterial diversity associated with calcareous deposits and drip-waters, and isolation of calcifying bacteria from two Colombian mines. Microbiological research, v. 182, p. 21-30, 2016. Disponível em: < http://dx.doi.org/10.1016/j.micres.2015.09.006>. doi: 10.1016/j.micres.2015.09.006 
GÓMEZ-MUÑETÓN, C. M. Uso de biotecnologia na melhoria de solos para fins de pavimentação rodoviária. 2009. Disponível em: <http://repositorio.unb.br/handle/10482/3992>.

GONZÁLEZ-KUNZ, R. N.; PINEDA, P.; BRAS, A.; MORILLAS, L. Plant biomass ashes in cement-based building materials. Feasibility as eco-efficient structural mortars and grouts. Sustainable Cities and Society, v. 31, p. 151-172, 2017. Disponível em: <http://dx.doi.org/10.1016/j.scs.2017.03.001>. doi: 10.1016/j.scs.2017.03.001

GOROSPE, C. M.; HAN, S. H.; KIM, S. G.; PARK, J. Y.; KANG, C. H.; JEONG, J. H.; SO, J. S. Effects of different calcium salts on calcium carbonate crystal formation by Sporosarcina pasteurii KCTC 3558. Biotechnology and bioprocess engineering, v. 18, n. 5, p. 903-908, 2013. Disponível em: <http://dx.doi.ogr/10.1007/s12257-0130030-0 > doi: 10.1007/s12257-013-0030-0

GRABIEC, A. M.; STARZYK, J.; STEFANIAK, K.; WIERZBICKI, J.; ZAWAL, D. On possibility of improvement of compacted silty soils using biodeposition method. Construction and Building Materials, v. 138, p. 134-140, 2017. Disponível em: $\quad$ <http://dx.doi.org/10.1016/j.conbuildmat.2017.01.071>. doi: 10.1016/j.conbuildmat.2017.01.071

GUPTA, V. K; NAYAK, A; AGARWAL, S. Bioadsorbents for remediation of heavy metals: current status and their future prospects. Environmental Engineering Research, v. 20, n. 1, p. 1-8, 2015. Disponível em: <https://doi.org/10.4491/eer.2015.018>. doi: 10.4491/eer.2015.018

HAMDAN, N.; KAVAZANJIAN, E.; RITTMANN, B. E. Sequestration of radionuclides and metal contaminants through microbially-induced carbonate precipitation. Toronto: Pan-Am CGS Geotechnical conference; 2011.

HAMDAN, N.; KAVAZANJIAN, J. E.; RITTMANN, B. E.; KARATAS, I. Carbonate mineral precipitation for soil improvement through microbial denitrification. Geomicrobiology Journal, v. 34, n. 2, p. 139-146, 2017. Disponível em: <http://dx.doi.org/10.1080/01490451.2016.1154117>. doi: 10.1080/01490451.2016.1154117>.

HAMMES, F.; BOON, N.; VILLIERS, J.; VERSTRAETE, W.; SICILIANO, S. D. Strainspecific ureolytic microbial calcium carbonate precipitation. Applied and environmental microbiology, v. 69, n. 8, p. 4901-4909, 2003. Disponível em: <http://dx.doi.org/10.1128/AEM.69.8.4901-4909.2003>. doi: 10.1128/AEM.69.8.49014909.2003

HELMI, F. M.; ELMITWALLI, H. R.; ELNAGDY, S. M.; EL-HAGRASSY, A. F. Calcium carbonate precipitation induced by ureolytic bacteria Bacillus licheniformis. Ecological Engineering, v. 90, p. 367-371, 2016. Disponível em: $<$ http://dx.doi.org/10.1016/j.ecoleng.2016.01.044>. doi: 10.1016/j.ecoleng.2016.01.044 
IVANOV, V.; CHU, J.; STABNIKOV, V. Basics of construction microbial biotechnology. In: Biotechnologies and biomimetics for civil engineering. Springer International Publishing, 2015. p. 21-56. Disponível em: <https://link.springer.com/chapter/10.1007/978-3-319-09287-4_2>. doi: 10.1007/9783-319-09287-4_2

JAGADEESHA KUMAR, B. G.; PRABHAKARA, R.; PUSHPA, H. Bio mineralisation of calcium carbonate by different bacterial strains and their application in concrete crack remediation. International Journal of Advances in Engineering \& Technology, Março, 2013. Disponível em: $<$ http://citeseerx.ist.psu.edu/viewdoc/download?doi=10.1.1.384.8054\&rep=rep1\&type $=$ pdf $>$.

JIANG, N. J.; SOGA, K. The applicability of microbially induced calcite precipitation (MICP) for internal erosion control in gravel-sand mixtures. Géotechnique, v. 67, n. 1, p. 42-55, 2016. Disponível em: <http://dx.doi.org/10.1680/jgeot.15.P.182>. doi: 10.1680/jgeot.15.P.182

JIANG, N.J.; YOSHIOKA, H.; YAMAMOTO, K.; SOGA, K. Ureolytic activities of a urease-producing bacterium and purified urease enzyme in the anoxic condition: Implication for subseafloor sand production control by microbially induced carbonate precipitation (MICP). Ecological Engineering, v. 90, p. 96-104, 2016. Disponível em: <http://dx.doi.org/10.1016/j.ecoleng.2016.01.073>. doi: 10.1016/j.ecoleng.2016.01.073

KANG, C. H.; HAN, S. H.; SHIN, Y. J.; OH, S. J.; SO, J. S. Bioremediation of Cd by microbially induced calcite precipitation. Applied biochemistry and biotechnology, v. 172, n. 6, p. 2907-2915, 2014. Disponível em: <http://dx.doi.org/10.1007/s12010014-0737-1>. doi: 10.1007/s12010-014-0737-1

KIM, G.; YOUN, H. Microbially induced calcite precipitation employing environmental isolates. Materials, v. 9, n. 6, p. 468, 2016. Disponível em: <http://dx.doi.org/10.3390/ma9060468>. doi: 10.3390/ma9060468

KHODADADI, H.; BILSEL, $H$. Application of microorganisms for improvement of liquefiable sand. In: Proceedings of the 3rd international conference on new developments in soil mechanics and geotechnical engineering. Near East University, Nicosia, North Cyprus. 2012. Disponível em: <https://zm2012.neu.edu.tr/ZM2012\%20DVD/New\%20Methods\%20in\%20GE/110.pd $\mathrm{f}>$.

KRAJEWSKA, B. Ureases I. Functional, catalytic and kinetic properties: A review. Journal of Molecular Catalysis B: Enzymatic, v. 59, n. 1, p. 9-21, 2009. Disponível em: <http://dx.doi.org/10.1016/j.molcatb.2009.01.003>. doi: 10.1016/j.molcatb.2009.01.003

KRISHNAPRIYA, S.; VENKATESH-BADU, D. L.; PRINCE, G. A. Isolation and identification of bacteria to improve the strength of concrete. Microbiological research, v. 174, p. 48-55, 2015. Disponível em: <http://dx.doi.org/10.1016/j.micres.2015.03.009>. doi: 10.1016/j.micres.2015.03.009 
LAUCHNOR, E. G.; SCHULTZ, L. N.; BUGNI, S.; MITCHELL, A. C.; CUNNINGHAM, A. B.; GERLACH, R. Bacterially induced calcium carbonate precipitation and strontium coprecipitation in a porous media flow system. Environmental science \& technology, v. 47, n. 3, p. 1557-1564, 2013. Disponível em: <http://scholarworks.montana.edu/xmlui/handle/1/12477>. doi: 10.1021/es304240y

LE-METAYER-LEVREL, G.; CASTANIER, S.; ORIAL, G.; LOUBIÈRE, J. F.; PERTHUISOT, J. P. Applications of bacterial carbonatogenesis to the protection and regeneration of limestones in buildings and historic patrimony. Sedimentary geology, v. 126, n. 1, p. 25-34, 1999. Disponível em: <http://dx.doi.org/10.1016/S0037-0738(99)00029-9>. doi: 10.1016/S00370738(99)00029-9

LEONARD, J. Increased rate of EOR brightens outlook. Oil Gas J.;(United States), v. 84, n. 15, 1986. Disponível em: <https://www.osti.gov/scitech/biblio/5848246>.

LI, M.; CHENG, X.; GUO, H. Heavy metal removal by biomineralization of urease producing bacteria isolated from soil. International Biodeterioration \& Biodegradation, v. 76, p. 81-85, 2013. Disponível em: <http://dx.doi.org/10.1016/j.ibiod.2012.06.016>. doi: 10.1016/j.ibiod.2012.06.016

LÓPEZ, I. Tratamiento de un suelo con Bacillus pasteurii. Efecto de la humedad y la porosidad. Diss., Universidad Nacional de Colombia, Medellín, Colombia, 2008.

MANI, D.; KUMAR, C. Biotechnological advances in bioremediation of heavy metals contaminated ecosystems: an overview with special reference to phytoremediation. International Journal of Environmental Science and Technology, v. 11, n. 3, p. 843-872, 2014. Disponível em: <http://dx.doi.org/10.1007/s13762-013-0299-8>. doi: 10.1007/s13762-013-0299-8

MANN, S. Biomineralization: principles and concepts in bioinorganic materials chemistry. Oxford University Press on Demand, 2001.

MIGLIARDINI, F.; DE LUCA, V.; CARGINALE, V.; ROSSI, M.; CORBO, P.; SUPURAN, C. T.; CAPASSO, C. Biomimetic $\mathrm{CO}_{2}$ capture using a highly thermostable bacterial $\alpha$-carbonic anhydrase immobilized on a polyurethane foam. Journal of enzyme inhibition and medicinal chemistry, v. 29, n. 1, p. 146-50, 2014. Disponível em: <http://dx.doi.org/10.3109/14756366.2012.761608>. doi: 10.3109/14756366.2012.761608

MOBLEY, H. L.; ISLAND, M. D.; HAUSINGER, R. P. Molecular biology of microbial ureases. Microbiological reviews, v. 59, n. 3, p. 451-480, 1995. Disponível em: $<$ http://mmbr.asm.org/content/59/3/451.short>.

NONAKARAN, S. H.; PAZHOUHANDEH, M.; KEYVANI, A.; ABDOLLAHIPOUR, F. Z.; SHIRZAD, A. Isolation and identification of Pseudomonas azotoformans for induced calcite precipitation. World Journal of Microbiology and Biotechnology, v. 31, n. 12, p. 1993-2001, 2015. Disponível em: <http://dx.doi.org/10.1007/s11274015-1948-5>. doi: 10.1007/s11274-015-1948-5 
NOSOUHIAN, F.; MOSTOFINEJAD, D.; HASHEMINEJAD, $\mathrm{H}$. Influence of biodeposition treatment on concrete durability in a sulphate environment. Biosystems Engineering, v. 133, p. 141-152, 2015. Disponível em: <http://dx.doi.org/10.1016/j.biosystemseng.2015.03.008>. doi: 10.1016/j.biosystemseng.2015.03.008

OKWADHA, G. D. O.; LI, J. Optimum conditions for microbial carbonate precipitation. Chemosphere, v. 81, n. 9, p. 1143-1148, 2010. Disponível em: <http://dx.doi.org/10.1016/j.chemosphere.2010.09.066>. 10.1016/j.chemosphere.2010.09.066

PACHECO-TORGAL, F.; LABRINCHA, J. A. Biotech cementitious materials: some aspects of an innovative approach for concrete with enhanced durability. Construction and Building Materials, v. 40, p. 1136-1141, 2013. Disponível em < http://dx.doi.org/10.1016/j.conbuildmat.2012.09.080>.

doi: 10.1016/j.conbuildmat.2012.09.080

PARK, S. J.; PARK, Y. M.; CHUN, W. Y.; KIM, W. J.; GHIM, S. Y. Calcite-forming bacteria for compressive strength improvement in mortar. Journal of microbiology and biotechnology, v. 20, n. 4, p. 782-788, 2010. Disponível em: <http://europepmc.org/abstract/med/20467254>.

PHILLIPS, A. J.; LAUNCHNOR, E.; ELDRING, J.; ESPOSITO, R.; MITCHELL, A. C. Potential $\mathrm{CO} 2$ leakage reduction through biofilm-induced calcium carbonate precipitation. Environmental science \& technology, v. 47, n. 1, p. 142-149, 2012. Disponível em: <http://dx.doi.org/10.1021/es301294q>. doi: 10.1021/es301294q

PHILLIPS, A. J.; GERLACH, R.; LAUCHNOR, E.; MITCHELL, A. C.; CUNNINGHAM, A. B.; SPANGLER, L. Engineered applications of ureolytic biomineralization: a review. Biofouling, v. 29, n. 6, p. 715-733, 2013. Disponível em: <http://dx.doi.org/10.1080/08927014.2013.796550>. $10.1080 / 08927014.2013 .796550$

POUGET, E. M.; BOMANS, P. H. H.; GOOS, J. A. C. M.; FREDERIK, P. M.; DE WITH, G.; SOMMERDIJK, N. A. J. M. The initial stages of template-controlled CaCO3 formation revealed by cryo-TEM. Science, v. 323, n. 5920, p. 1455-1458, 2009. Disponível em: <http://dx.doi.org/10.1126/science.1169434>. doi: 10.1126/science.1169434

PRESCOTT, L. M.; HARLEY, J. P.; KLEIN, D. A. Microbiology. Dubuque, US, 1993.

RAMACHANDRAN, S. K.; RAMAKRISHNAN, V.; BANG, S. S. Remediation of concrete using micro-organisms. ACI Materials Journal-American Concrete Institute, v. 98, n. 1, p. 3-9, 2001. Disponível em: <http://sphinx.murdoch.edu.au/units/extern/BIO301/teach/download/previous\%20yea rs/Chemostat/B.\%20pasteuri\%20literature\%20examples/Concrete\%20remediation\% 20with\%20B.\%20pasteurii.pdf> 
REDDY, M. S. Biomineralization of calcium carbonates and their engineered applications: a review. Frontiers in Microbiology, v. 4, p. 314, 2013. Disponível em < https://doi.org/10.3389/fmicb.2013.00314>. doi: 10.3389/fmicb.2013.00314

RODRIGUEZ-NAVARRO, C.; JROUNDI, F.; GONZALEZ-MUÑOZ, M. T. Stone Consolidation by Bacterial Carbonatogenesis: Evaluation of in situ Applications. Restoration of Buildings and Monuments, v. 21, n. 1, p. 9-20, 2015. Disponível em: <https://doi.org/10.1515/rbm-2015-0002>. doi: 10.1515/rbm-20150002

RODRIGUEZ-NAVARRO, C.; JIMENEZ-LOPES, C.; RODRIGUEZ-NAVARRO, A.; GONZALEZ-MUÑOZ, M. T.; RODRIGUEZ-GALLEGO, M. Bacterially mediated mineralization of vaterite. Geochimica et Cosmochimica Acta, v. 71, n. 5, p. 11971213, 2007. Disponível em: <http://dx.doi.org/10.1016/j.gca.2006.11.031>. doi: 10.1016/j.gca.2006.11.031

SHARMA, S.; SINGH, B.; MANCHANDA, V. K. Phytoremediation: role of terrestrial plants and aquatic macrophytes in the remediation of radionuclides and heavy metal contaminated soil and water. Environmental Science and Pollution Research, v. 22, n. 2, p.946-962, 2015. Disponível em: <http://dx.doi.org/ 10.1007/s11356-0143635-8 >. doi: 10.1007/s11356-014-3635-8

SHARMA, T. K.; ALAZHARI, M.; HEATH, A.; PAINE, K.; COOPER, R. M. Alkaliphilic Bacillus species show potential application in concrete crack repair by virtue of rapid spore production and germination then extracellular calcite formation. Journal of Applied Microbiology, 2017. Disponível em: <http://dx.doi.org/10.1111/jam.13421>. doi: 10.1111/jam.13421

SINGH, A.; PRASAD, S. M. Remediation of heavy metal contaminated ecosystem: an overview on technology advancement. International Journal of Environmental Science and Technology, v. 12, n. 1, p. 353-366, 2015. Disponível em: <http://dx.doi.org/10.1007/s13762-014-0542-y>. doi: 10.1007/s13762-014-0542-y

SOON, N. W.; LEE, L. M.; KHUN, T. C.; LING, H. S. Improvements in engineering properties of soils through microbial-induced calcite precipitation. KSCE Journal of Civil Engineering, v. 17, n. 4, p. 718-728, 2013. Disponível em: <http://dx.doi.ogr/10.1007/s12205-013-0149-8>. doi: 10.1007/s12205-013-0149-8

SOON, N. G.; LEE, L. M.; KHUN, T. C.; LING, H. S. Factors affecting improvement in engineering properties of residual soil through microbial-induced calcite precipitation. Journal of Geotechnical and Geoenvironmental Engineering, v. 140, n. 5, p. 04014006, 2014. Disponível em: <http://ascelibrary.org/doi/pdf/10.1061/(ASCE)GT.1943-5606.0001089>.

STABNIKOV, V.; JIAN, C.; IVANOV, V.; LI, Y. Halotolerant, alkaliphilic ureaseproducing bacteria from different climate zones and their application for biocementation of sand. World Journal of Microbiology and Biotechnology, v. 29, n. 8, p. 1453-1460, 2013. Disponível em: <http://dx.doi.org/10.1007/s11274-0131309-1>. doi: 10.1007/s11274-013-1309-1 
STOCKS-FISCHER, S.; GALINAT, J. K.; BANG, S. S. Microbiological precipitation of $\mathrm{CaCO}_{3}$. Soil Biology and Biochemistry, v. 31, n. 11, p. 1563-1571, 1999. Disponível em: <http://dx.doi.org/10.1016/S0038-0717(99)00082-6>. doi: 10.1016/S0038-0717(99)00082-6

USON, A. A. LÓPEZ-SABIRÓN, A. M.; FERREIRA, G.; SASTRESA, E. L. Uses of alternative fuels and raw materials in the cement industry as sustainable waste management options. Renewable and Sustainable Energy Reviews, v. 23, p. 242260, 2013. Disponível em: <http://dx.doi.org/10.1016/j.rser.2013.02.024>. doi: 10.1016/j.rser.2013.02.024

VON AHNEN, M.; PEDERSEN, L. F.; PEDERSEN, P. B.; DALSGAARD, J. Degradation of urea, ammonia and nitrite in moving bed biofilters operated at different feed loadings. Aquacultural Engineering, v. 69, p. 50-59, 2015. Disponível em: $\quad<$ http://dx.doi.org/10.1016/j.aquaeng.2015.10.004>. doi: 10.1016/j.aquaeng.2015.10.004

WARTHMANN, R.; LITH, Y. V.; VASCONCELOS, C.; MCKENZIE, J. A.; KARPOFF, A. M. Bacterially induced dolomite precipitation in anoxic culture experiments. Geology, v. 28, n. 12, p. 1091-1094, 2000. Disponível em: <http://geology.gsapubs.org/content/28/12/1091.short>. doi: 10.1130/0091$7613(2000) 28$

YANG, J.; PAN, X.; ZHAO, C.; MOU, S.; ACHAL, V.; AL-MISNED, F. A.; MORTUZA, M. G.; GAAD, G. M. Bioimmobilization of heavy metals in acidic copper mine tailings soil. Geomicrobiology Journal, v. 33, n. 3-4, p. 261-266, 2016. Disponível em: <http://dx.doi.org/10.1080/01490451.2015.1068889>. doi: 10.1080/01490451.2015.1068889

ZHONG, L.; ISLAM, M. R. A new microbial plugging process and its impact on fracture remediation. In: SPE Annual Technical Conference and Exhibition. Society of Petroleum Engineers, 1995. Disponível em: <https://www.onepetro.org/conference-paper/SPE-30519-MS>.

ZHU, X.; LI, W.; ZHAN, L.; HUANG, M.; ZHANG, Q.; ACHAL, V. The large-scale process of microbial carbonate precipitation for nickel remediation from an industrial soil. Environmental Pollution, v. 219, p. 149-155, 2016. Disponível em: <http://dx.doi.org/10.1016/j.envpol.2016.10.047>. doi: 10.1016/j.envpol.2016.10.047 